\title{
The Focal Encephalopathies Associated with Mycoplasma Pneumoniae
}

\author{
Raj D. Sheth, Keith J. Goulden and William E. Pryse-Phillips
}

\begin{abstract}
Five patients with evidence of focal encephalopathy are reported. In each case, evidence of mycoplasma pneumoniae infection was detected. No patient improved with conventional antibiotic therapy, but in three subjects, rapid and complete recovery did occur contemporaneously with the administration of high dose steroid therapy. It is suggested that focal as well as diffuse cerebral or cerebellar lesions may occur as manifestations of auto-immune disease complicating mycoplasmal infections in young people and that this illness may be designated as acute mycoplasmaassociated encephalopathy.
\end{abstract}

RÉSUMÉ: Encéphalopathies focales à mycoplasma pneumoniae. Nous rapportons les cas de cinq patients présentant une encéphalopathie focale. Dans chaque cas, des signes d'infection à Mycoplasma pneumoniae ont été détectés. Aucun patient ne s'est amélioré sous antibiothérapie conventionnelle. Cependant, chez trois patients, une guérison rapide et complète a été obtenue alors que le patient était sous corticothérapie intensive. Nous suggérons que des lésions focales et des lésions diffuses peuvent survenir au niveau du cerveau ou du cervelet comme manifestations d'une maladie auto-immune compliquant l'infection à mycoplasme chez les jeunes et que cette maladie pourrait être désignée sous le nom d'encéphalopathie aiguë associée au mycoplasme.

Can. J. Neurol. Sci. 1993; 20:319-323

Mycoplasma pneumoniae is a recognized cause of acute respiratory infections of all degrees of severity, and is sometimes complicated by skin, cardiac, gastro-intestinal, articular or hematological problems. Central nervous system complications recorded have included meningo-encephalitis, cerebellitis, meningitis, polyradiculitis, transverse myelitis, cranial nerve palsies and acute psychoses. ${ }^{1.2}$ We describe five additional patients with atypical clinical findings and suggest that mycoplasmal encephalopathy is a condition meriting serious consideration in patients with encephalopathy which cannot be classified as being typically encephalitic; post-infectious, or parainfectious noninflammatory in nature. ${ }^{3}$

Mycoplasma pneumoniae is increasingly recognized as a cause of encephalopathy in childhood, especially since the decline in polio, measles, rubella and pertussis as a result of successful immunization programs..$^{4-6}$ In a large series this agent accounted for a third of the encephalitides occurring after age 10 years and in which a pathogen had been identified. ${ }^{7}$ The pathogenesis of mycoplasma-associated encephalopathy (MPAE) remains unclear since mycoplasma has seldom been isolated from the blood or CSF. ${ }^{8-11}$ The clinical features of MPAE are usually those of diffuse nervous system involvement; focal manifestations have been reported occasionally but are poorly characterized.

We report some varied syndromes including focal encephalopathy, in 5 children or youths with serological evidence of recent mycoplasmal infection. While two of them made a spontaneous recovery, 3 children suffered a progressive neurological deterioration that reversed only after the initiation of corticosteroid therapy, despite treatment with erythromycin. We describe the clinical features of these subjects with MPAE and provide evidence supporting an autoimmune para-infectious pathogenesis.

\section{CASE REPORTS}

\section{Patient 1}

A 5.8-year-old girl, (Tables 1,2) who was in good health until she developed a throbbing right periorbital pain 5 weeks before presentation. At that time there was also a two week history of abulia and dulling of affect. On examination she was afebrile; frontal release signs were present and she had meningismus and a right afferent pupillary defect with optic papillitis on fundoscopy. Her visual acuity was $20 / 300$. There were bilateral upper motor neuron signs (hyperreflexia and extensor plantar responses) and urinary incontinence was also present. There was peripheral leukocytosis ( $82 \%$ neutrophils): the ESR was 53. A mycoplasma infection was confirmed serologically (acute $\operatorname{IgM}>1: 320$, convalescent $\lg M<1: 40$ ). Extensive investigation for other specific infections, collagen vascular diseases and leukodystrophies was negative. The CSF, obtained on day 4 of her illness, showed pleocytosis $(\mathrm{WBC}=113)$, increased RBCs with xanthochromia and an elevation of protein $(0.4 \mathrm{~g} / \mathrm{L})$ but oligoclonal bands were absent. All cultures were negative. Lyme disease is not reported in Newfoundland, but since she had been out of the Province in the last year, the titre was performed and was negative. An EEG showed diffuse delta activity and the visual evoked potential (VEP - PI00) was markedly slowed in the right eye. Nerve conduction velocities and

From the Divisions of Pediatrics and Neurology, Memorial University of Newfoundland, St. John's, Newfoundland

Received February 25, 1993. Accepted in final form June 8, 1993

Reprint requests to: Dr. Raj D. Sheth, Dept. of Neurology and Pediatrics, West Virginia University, Morgantown, WV 26506-9180 USA 
Table 1. Summary of Clinical and Laboratory Features in 5 Patients With Mycoplasma Pneumoniae Associated Focal Encephalitis

\begin{tabular}{|c|c|c|c|}
\hline $\begin{array}{l}\text { Patient, Age } \\
\text { Antecedent }\end{array}$ & Diagnosis & Laboratory studies & $\mathrm{CSF}$ \\
\hline $\begin{array}{l}\mathbf{1}, 5.8 \text { y } \\
\text { None }\end{array}$ & $\begin{array}{l}\text { Right optic neuritis } \\
\text { Acute hemorrhagic } \\
\text { leukoencephalitis }\end{array}$ & $\begin{array}{l}\text { WBC } 30,000, \\
\text { ESR 53, D-DNA Ab } \\
\text { negative }\end{array}$ & $\begin{array}{l}\text { OP } 360 \\
\text { RBC } 23 \text {, WBC } 113(80 \% \mathrm{~L}) \\
\text { Glu } 3.2 \text {, Prot } 0.46\end{array}$ \\
\hline $\begin{array}{l}2,6 \text { y } \\
\text { Pneumonia }\end{array}$ & $\begin{array}{l}\text { Post infectious } \\
\text { cerebellitis }\end{array}$ & WBC 7,000 & $\begin{array}{l}\text { OP not done, } \\
\text { RBC } 15, \text { WBC } 0 \\
\text { Glu } 3.9 \text {, Prot } 0.25\end{array}$ \\
\hline $\begin{array}{l}3,15 y \\
\text { URI for } 3 w k s\end{array}$ & $\begin{array}{l}\text { Focal right cortical } \\
\text { lesion }\end{array}$ & WBC 8,000 & Not done \\
\hline $\begin{array}{l}4,16 \mathrm{y} \\
\text { URI for } 2 w \mathrm{ks}\end{array}$ & $\begin{array}{l}\text { Focal right cortical } \\
\text { and thalamic } \\
\text { lesions }\end{array}$ & $\begin{array}{l}\text { WBC } 17,000, \text { ESR } 58, \\
\text { VDRL false }+, \\
\text { A-DNA Ab negative }\end{array}$ & $\begin{array}{l}\text { OP } 260 \\
\text { RBC 3, WBC } 177(90 \% \text { L) } \\
\text { Glu 3.0, Prot } 0.75\end{array}$ \\
\hline $\begin{array}{l}5,11 \text { y } \\
\text { None }\end{array}$ & $\begin{array}{l}\text { Focal right } \\
\text { cerebellitis }\end{array}$ & $\begin{array}{l}\text { WBC } 16,000 \\
\text { ESR } 30\end{array}$ & $\begin{array}{l}\text { OP } 160 \\
\text { RBC } 144, \text { WBC } 1 \\
\text { Glu } 3.6\end{array}$ \\
\hline
\end{tabular}

Abbreviations: $\mathrm{ESR}=$ sedimentation rate $($ Westergren $), \mathrm{Glu}=$ glucose in $\mathrm{mmol} / \mathrm{l}$, Prot $=$ protein in $\mathrm{g} / \mathrm{l}$, $\mathrm{OP}=$ opening pressure in $\mathrm{mm}$ of water, $\mathrm{L}=$ lymphocytes, $\mathrm{Ig}=$ immunoglobulin, A-DNA $\mathrm{Ab}=$ anti DNA antibodies, Conv $=$ convalescent, $\mathrm{URI}=$ upper respiratory infection.

Table 2. Summary of Clinical and Laboratory Features in 5 Patients With Mycoplasma Pneumoniae Associated Focal Encephalitis

\begin{tabular}{|c|c|c|c|}
\hline EEG & Imaging & Resolution & $\begin{array}{l}\text { Mycoplasma } \\
\text { Serology }\end{array}$ \\
\hline $\begin{array}{l}\text { Diffuse delta } \\
\text { slowing }\end{array}$ & $\begin{array}{l}\text { CT normal } \times 3 \\
\text { MRI mild diffuse atrophy (post } \\
\text { steroids) }\end{array}$ & with steriods & $\begin{array}{l}\text { Acute IgM } 1: 320 \\
\text { Conv IgM }<1: 40\end{array}$ \\
\hline Normal & CT normal & Spontaneous & $\begin{array}{l}\text { Acute } \mathrm{IgM} 1: 1280 \\
\text { Conv refused }\end{array}$ \\
\hline $\begin{array}{l}\text { Right frontal } \\
\text { slowing }\end{array}$ & $\begin{array}{l}\text { CT ring enhancing right frontal } \\
\text { and left parietal lobes lesions }\end{array}$ & with steroids & $\begin{array}{l}\text { Acute } \operatorname{IgM} 1: 160 \\
\text { Conv } \operatorname{IgM}<1: 40\end{array}$ \\
\hline $\begin{array}{l}\text { Right } \\
\text { hemisphere } \\
\text { slowing }\end{array}$ & $\begin{array}{l}\text { CT normal } \times 2 \\
\text { MRI normal (post steroids) }\end{array}$ & with steroids & $\begin{array}{l}\text { Acute } \operatorname{IgM} 1: 160 \\
\text { Conv } \operatorname{IgM}<1: 40\end{array}$ \\
\hline Normal & $\begin{array}{l}\text { MRI edema right cerebellar } \\
\text { hemisphere }\end{array}$ & Spontaneous & $\begin{array}{l}\text { Acute IgM } 1: 160 \\
\text { Conv IgM }<1: 40\end{array}$ \\
\hline
\end{tabular}

Abbreviations: $\mathrm{ESR}=$ sedimentation rate (Westergren), Glu $=$ glucose in $\mathrm{mmol} / \mathrm{l}$, Prot $=$ protein in $\mathrm{g} / \mathrm{l}$, $\mathrm{OP}=$ opening pressure in $\mathrm{mm}$ of water, $\mathrm{L}=$ lymphocytes, $\mathrm{Ig}=$ immunoglobulin, A-DNA $\mathrm{Ab}=$ anti DNA antibodies, Conv $=$ convalescent, $\mathrm{URI}=$ upper respiratory infection.

EMG were normal. Intravenous ceftriaxone, erythromycin and gentamycin did not halt the progression of her symptoms.

A 10 day course of $10 \mathrm{mg} / \mathrm{kg} /$ day of intravenous methylprednisolone was started on day 11 of her illness. By day 14 she showed remarkable improvement and by day 23 she had completely recovered symptomatically. Repeat EEG, VEP and CSF analysis were normal. At 17-month follow up she had not relapsed but there was some evidence of a new learning disability. Follow-up MRI and CT scans showed static, mild, diffuse cerebral atrophy.

In summary, the clinical picture of optic neuritis and diffuse encephalopathy with pyramidal signs was quickly reversed with intravenous steroids.

\section{Patient 2}

A 6-year-old boy who presented with a history of 2 days of clumsiness and difficulty in walking. Three weeks earlier he had completed a 10 day course of erythromycin for mycoplasma pneumoniae respiratory infection confirmed by chest X-ray. On examination he had cerebellar ataxia, horizontal gaze nystagmus and meningismus without fever. The
CSF opening pressure was not measured but analysis was normal.

Over a two week period there was a spontaneous resolution of symptoms and he became completely normal. At follow up 16 months later he showed no evidence of relapse. It was considered that he had suffered a post-infectious cerebellitis with onset 10 days after treatment with erythromycin for pneumonia.

\section{Patient 3}

A left-handed, 15-year-old male who presented with the complaint of 3 weeks of headache and neck pain. Two weeks prior to the onset of these symptoms he had completed a 10 day course of erythromycin for a mycoplasmal respiratory infection, confirmed by chest X-ray; this had resolved. On admission he had meningismus but was afebrile, alert and fully orientated. There was expressive aphasia with left hemiparesis and impaired graphesthesia and stereognosis on the left. A contrastenhanced CT scan (Figure la) revealed right frontal and left parietal ring-enhancing lesions. An abscess or tumor was suspected and it was thought that CSF could not be obtained safely. At surgery, the right frontal lobe protruded through the craniotomy and a cystic cavity with 
xanthochromic fluid was found beneath the cortex. No purulent material was present and all cultures were negative. On brain biopsy, sterile xanthochromic fluid surrounded only by reactive gliosis was found.

A 10 day course of intravenous erythromycin, metronidazole, cloxacillin and ceftriaxone was completed but he continued to deteriorate. He was then given prednisone $(1 \mathrm{mg} / \mathrm{kg} /$ day $)$; initial improvement was noted within 72 hours and over the next week, full clinical recovery ensued. Maintenance prednisone for 6 weeks was followed by tapering doses. His symptoms completely resolved with steroid therapy and on repeat CT scanning, the cystic lesion had shrunk to a small defect, while the other lesion was no longer visible (Figure $\mathrm{lb}$ ). Right frontal slowing persisted on the EEG. He later developed complex partial seizures and classic migraine which have been well controlled respectively with carbamazepine and atenolol. Neuropsychological testing 11 months after the initial illness showed a full scale $1 Q$ of 98 (Verbal $=101$ and Performance $=94$ ). At 21 -month follow up he has not shown any evidence of relapse.

In summary, focal cerebral deficits occurred 21 days after a mycoplasmal respiratory illness and cleared completely only after intravenous steroid therapy.

\section{Patient 4}

A 16-year-old girl (Tables I, 2) who presented with a 2 week history of progressive throbbing headache, made worse by Valsalva maneuvers, diplopia on left gaze and episodes of left hemianesthesia. Two weeks earlier she had had an upper respiratory infection which spontaneously resolved. On examination, she had meningismus and photophobia but was afebrile. She described intermittent sensory loss to all modalities on the left side. Repeated CT scan examinations were normal but an EEG showed right frontotemporal delta activity. There was a mild CSF lymphocytic pleocytosis with a normal glucose and elevation of opening pressure and of protein. All cultures of CSF and blood were negative.

A diagnosis of herpes encephalitis was made and she was treated with acyclovir, but later with erythromycin after a mycoplasma IgM titer of $1: 160$ was reported. However, her symptoms progressed and she developed a new left hemiparesis concurrent with right hemisphere delta slowing on EEG. She was then started on oral dexamethasone at $0.5 \mathrm{mg} / \mathrm{kg} / \mathrm{day}$ with dramatic resolution of most symptoms within 24 hours and of all symptoms within 4 days. An MRI scan done at this time was normal. At a 12 month follow up she remains asymptomatic.

In summary, 14 days after a mycoplasmal respiratory infection, this patient developed a right hemiparesis which cleared within 2 days with steroid therapy.

\section{Patient 5}

An 11-year-old boy, who was in good health until he presented with a 10 day history of headache, the features of which suggested elevated intracranial pressure; and diplopia on right lateral gaze. He had meningismus with photophobia but was afebrile. Horizontal nystagmus was prominent on right lateral gaze. There was right arm dysmetria on finger-nose testing but heel-shin testing was normal. A mycoplasma infection was diagnosed serologically (acute $\operatorname{lgM} 1$ : 160, convalescent $1: 40$ ). An EEG was normal. A CT scan showed a decrease in the volume of the subarachnoid space in the posterior fossa. The fourth ventricle was displaced to the left so CSF analysis was deferred. Over the next 10 days his symptoms spontaneously improved. An MRI scan obtained at this time showed swelling and an increased T2 signal in the right cerebellar hemisphere (see Figure 2). CSF analysis was performed after he had almost completely recovered and was normal.

In summary, a right cerebellopathy occurred in a patient without any identified respiratory antecedent, but cleared spontaneously.

\section{Discussion}

We report 5 young patients with serologically-confirmed, mycoplasma-associated encephalopathy among a total mycoplasma sero-positive population of 108 children seen in our province over a 24 month period. Four children showed a four-fold or greater decrease in IgM class antibodies (measured by an indirect particle agglutination technique, Serodia Myco

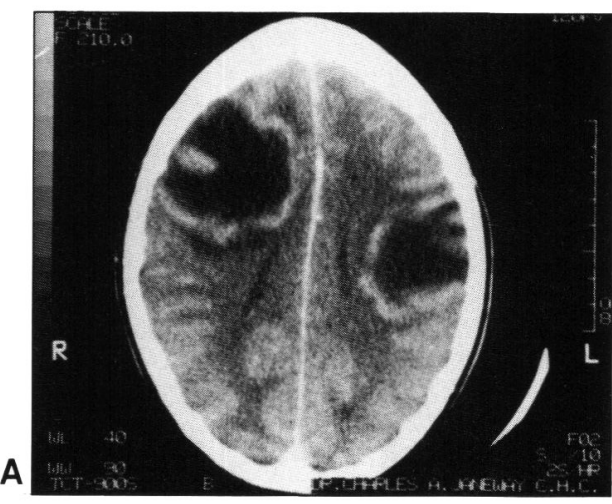

Figure IA - Patient 3. Contrast enhanced CT scan showing ring enhancement in the right frontal and left parietal lobes.

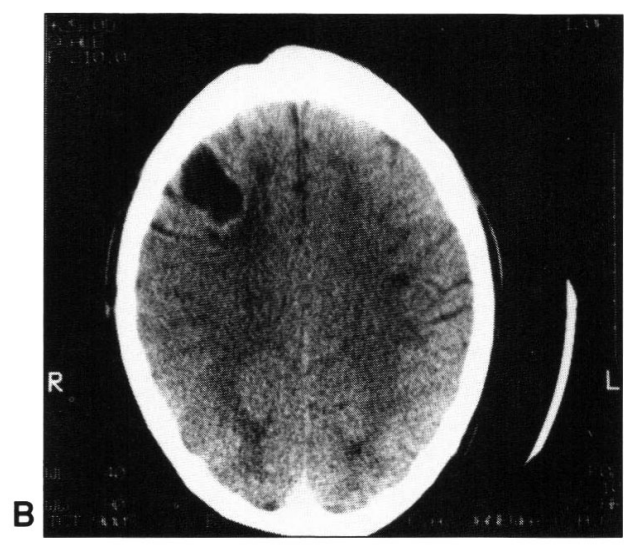

Figure IB - Patient 3. Unenhanced CT scan. at 17 month follow'-up there is complete resolution of the left parietal lobe lesion and a residual deficit in the right fromtal at the site of biopsy.

$\mathrm{II}^{\mathrm{R}}$, Miles Canada) for mycoplasma; the parents of patient 2 refused to allow a convalescent blood sample to be taken. Complement fixation, IgG class antibodies and DNA probe studies for mycoplasma were not performed. The ages of the 3 males and 2 females ranged between 5.8 and 16 years.

In three cases, (patients 2,3 , and 4 ) a febrile respiratory tract mycoplasmal infection (which resolved with erythromycin), preceded the onset of MPAE by 10 to 21 days. In all cases the onset of MPAE was heralded by a 7 to 14 day prodrome consisting of a change in affect, lethargy and subsequently signs of meningeal irritation. Remarkably, all of the children were afebrile, both prior to and during their encephalopathic illnesses. A focal encephalopathy was diagnosed on the basis of clinical examination, EEG, VEP or cerebral imaging.

Mycoplasmal cultures of the brain abscess aspirate obtained from patient 3 , in standard modified PPLO broth and $\operatorname{agar}^{10}$ and grown for one month, were negative. An extensive workup for collagen-vascular disease and for relevant infections was performed in each patient but was negative in each case. The EEG showed focal slowing in those children with cerebral involvement. Imaging showed focal lesions in 2 patients (patients 3 and 5) while three had normal CT and MRI scans. However, it may be 


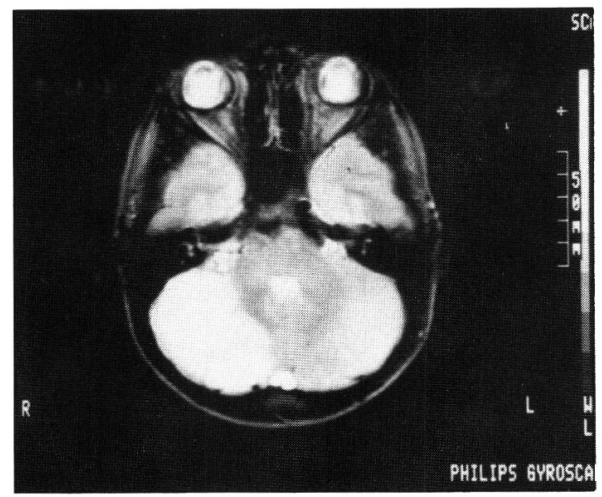

Figure 2 - Patient 5. MRI scan (T2 weighted image) demonstrates increased signal and swelling of the right cerebellar hemisphere with shift of the fourth ventricle.

noted that patients 1 and 4 were on steroids and had almost fully recovered at the time of their MRI scans. CSF analysis showed moderate lymphocytic pleocytosis with elevation of opening pressure and protein in 2 patients (patients 1 and 4) but was normal in patient 2 . Analysis was delayed until recovery in patient 5 (normal CSF) and was not done in patient 3 due to safety concerns.

Two patients (patients 3 and 5) recovered spontaneously, but the remaining three deteriorated while on intravenous antibiotics which included erythromycin. Steroids were started after at least 10 days of antibiotics and when it became clear that the encephalopathy was progressing. All five patients eventually had complete resolution of their symptoms. At follow up between 4 and 25 months, no patient has had a relapse, but 2 patients have residual deficits as a result of MPAE (focal seizures and migraine in patient 3 and a learning disability in patient 1).

Central nervous system complications of mycoplasmal infections occur in between 0.1 and $7 \%$ of reported cases. ${ }^{12}$ The diagnosis is almost impossible clinically but acute and convalescent serology titres are considered to be helpful diagnostically; a single titre of $1 / 64$ is also considered to be highly suggestive. ${ }^{2}$

Serologically-diagnosed mycoplasmal infections are established as a cause of CNS disease. ${ }^{4,13-15}$ The mechanism for mycoplasmal-associated CNS involvement is believed to be either direct invasion or an autoimmune process. Based on the direct invasion hypothesis, erythromycin has been the mainstay of therapy for MPAE. In a large series of patients with MPAE treated with erythromycin, the occurrence of death or severe neurological disability was 7 times that in other acute encephalitides. ${ }^{16,17}$ In fact, the pathogenesis of this illness is unknown, but four alternatives have been suggested: ${ }^{2}$ 1) Direct invasion of the brain seems unlikely in view of our findings, such as the lack of recovery of any organism from the brain parenchyma in any case, and from the CSF only seldom..$^{9-11}$ The concept of the secretion of an exotoxin by the mycoplasma is appealing, but again the response to steroids reported here and the absence of evidence of toxic effects on other tissues makes this hypothesis unattractive. 2) The effect of a neurotoxin; however, no such substance has been identified to date. 3) The presence of multiple vascular microthrombi seems unlikely in view of the rapid recovery of our patients treated with steroids and because of the paucity of evidence of systemic disease in subjects (such as those reported here) with severe encephalopathy but without evidence of disease affecting any other systems. 4) Many features of MPAE have suggested that this condition is the result of an autoimmune process. Some previous authors have advocated treatment with steroids and impressive responses have been reported. ${ }^{18.19}$ It is well known that mycoplasma causes agglutination of human erythrocytes (cold agglutinins), and has been associated with joint, cardiac and mucocutaneous manifestations that resemble collagen vascular disease. Mycoplasma has been associated with the Guillain Barré-syndrome, which is believed to have an autoimmune etiology. ${ }^{14}$ Mycoplasma has never been recovered from the CNS to our knowledge.

The presence of an autoimmune process is supported by the findings in our patients. While all of them had signs of meningeal inflammation, none had fever. Three had been treated successfully with erythromycin for mycoplasmal respiratory disease which had occurred 3 to 4 weeks prior to the encephalopathic symptoms. There was a lag period of 2 to 3 weeks before the onset of the prodromal neurological symptoms, as seen in other autoimmune manifestations, for example rheumatic fever. Two patients presented with syndromes generally recognized as having a post-infectious autoimmune etiology such as postinfectious cerebellitis and acute leukoencephalitis. In two cases there was obvious systemic involvement such as leukocytosis, a general elevation of serum immunoglobulin and an elevated sedimentation rate, without other focal deficits.

The findings in our series of patients may be regarded as evidence against direct infection. Normal CSF or only mild pleocytosis was seen in all cases and all cultures were negative. Patient 3 had a biopsy performed on his focal cerebral lesions which showed no purulent material. In our patients, erythromycin effectively cleared respiratory infections but failed to prevent the subsequent focal encephalopathy. In 3 of our 5 patients, once MPAE occurred, therapy with erythromycin for at least 10 days did not prevent progression. While penetration of the intact blood-brain barrier by erythromycin is poor, increased penetration occurs with inflammation. Improvement in these children only occurred after the administration of steroids. Two patients did not receive erythromycin during the period of MPAE but they recovered spontaneously. None of our patients has had a relapse with follow-up of between 4 and 25 months, although relapse was noted in a previously-reported child. ${ }^{18}$ Commonly reported neurological complications of mycoplasma pneumoniae include seizures, coma and meningeal signs ${ }^{7}$ while less common complications include status epilepticus with PLEDs ${ }^{20}$ encephalitis lethargica ${ }^{21}$ and stroke-like syndromes. ${ }^{22}$ Most reports of MPAE have described diffuse cerebral involvement, but in our experience focal manifestations are at least as common. We report a second patient (patient 3) with ringenhancing lesions on $\mathrm{CT}$, a finding first reported by Walker ${ }^{18}$ who was also unable to suggest a pathogenesis for the presence of cystic lesions in this condition.

Our patients bear some resemblance to those reported by Kepes, ${ }^{23}$ regarding both their clinical presentation and the CT findings, but that author did not comment on mycoplasma titers among his subjects, and in the single case biopsied in our series, no demyelinating changes were found. 
In conclusion, we emphasize that severe neurological impairment can occur in mycoplasma-associated encephalitis. While MPAE usually causes a diffuse encephalopathy, these cases reaffirm that focal brain disease can also occur. An autoimmune mechanism is probably responsible for MPAE. We suggest that in the face of progressive mycoplasma encephalopathy, a trial of steroids should be considered.

\section{ACKNOWLEDGEMENT}

We wish to thank Drs. William Sprague, Robert Morris and Adeleke Badejo who shared in the care of patient 3 .

\section{REFERENCES}

1. Fisher RS, Clark AW, Wolinsky JS, et al. Postinfectious leukoencephalitis complicating mycoplasma pneumoniae infections. Arch Neurol 1983; 40: 109-113.

2. Decaux G, Szyper M, Ectors M, Cornil A, Franken L. Central nervous system complications of mycoplasma pneumoniae. J Neurol Neurosurg Psychiatry 1980; 43: 883-887.

3. Ropper AH. Case Records of the Massachussetts General Hospital (35-1981). N Engl J Med 1981; 305: 507-514.

4. Cassell GH, Cole BC. Mycoplasmas as agents of human disease. $\mathrm{N}$ Engl J Med 1981; 302: 80-89.

5. Levine DP, Lerner AM. The clinical spectrum of mycoplasma pneumoniae inefections. Med Clin North Am 1978; 62: 961-978.

6. Lerer RJ, Kalavsky SM. Central nervous system disease associated with mycoplasma pneumoniae infections. Pediatrics 1973; 52: 658-668.

7. Koskiniemi M, Rautonen J, Lehtokoski-Lehtiniemi E, Vaheri A. Epidemiology of encephalitis in children - a 20-year survey. Ann Neurol 1991; 29: 492-497.

8. Waites KB, Duffy LB, Baldus K, Aronin PA. Mycoplasmal infections of cerebrospinal fluid in children undergoing neurosurgery for hydrocephalus. Pediatr Infect Dis J 1991;10: 952-953.

9. Nagayama Y, Sakurai N, Tamai K, et al. Isolation of mycoplasma pneumoniae from pleural fluid and/or cerebrospinal fluid: report of four cases. Scand J Infect Dis 1987; 19: 521-524.
10. Kasahara I, Otsubo Y, Yanase T, et al. Isolation and characterization of mycoplasma pneumoniae from cerebrospinal fluid of a patient with pneumonia and meningoencephalitis. J Infect Dis 1985 152: 823-825.

11. Abramovitz P, Schvartzman P, Harel D, et al. Direct invasion of the central nervous system by mycoplasma pneumoniae: a report of two cases. J Infect Dis 1987; 155: 482-487.

12. Sterner G, Biberfeld G. Central nervous system complications of mycoplasma pneumoniae infections. Scand J Infect Dis 1969; 1: 203-208.

13. Ponka A. Central nervous system manifestations associated with serologically-verified mycoplasma pneumoniae infection. J Infect Dis 1980; 12: 175-184.

14. Goldschmidt B, Menonna J, Fortunato J, Dowling P. Cook S. Mycoplasma antibody in Guillain-Barré syndrome and other neurological disorders. Ann Neurol 1979; 7: 108-112.

15. Urquhart GD. Mycoplasma pneumoniae infection and neurological complications. Brit Med J 1979; 2: 1512.

16. Rautonen J, Koskiniemi M, Vaheri A. Prognostic factors in childhood acute encephalitis. Pediatr Infect Dis J 1991; 10: 44 1-446.

17. Lehtokoski-Lehtiniemi E, Koskiniemi M. Mycoplasma pneumoniae encephalitis: a severe entity in children. Pediatr Infect Dis J 1989; 8: 651-653.

18. Walker RWH, Gawler J. Serial cerebral CT abnormalities in relapsing acute disseminated encephalomyelitis. I Neurol Neurosurg Psychiatry 1989; 52: 1100-1102.

19. Coleman RJ, Brown JS, Butler P, Swash M. Cerebellar syndrome with hydrocephalus due to mycoplasma pneumoniac infection. Postgrad Med J 1990; 66: 554-556.

20. Hulihan JF, Bebin EM, Westmoreland BF. Bilateral periodic lateralized epileptiform discharges in mycoplasma encephalitis. Pediatr Neurol 1992; 8: 292-294.

21. Al-Mateen M, Gibbs M, Dietrich R, Mitchell WG, Menkes JH. Encephalitis lethargica-like illness in a girl with mycoplasma infection. Neurology 1988; 38: 1155-1158.

22. Visudhiphan $P$, Chiemchanya S, Sirinavin S. Internal carotid artery occlusion associated with mycoplasma pneumoniae infection. Pediatr Neurol 1992; 8: 237-294.

23. Kepes JJ. Large focal tumor-like demyelinating lesions of the brain: intermediate entity between multiple sclerosis and acute disseminated encephalomyelitis? A study of 31 patients. Ann Neurol 1993; 33: 18-27. 